\title{
Canada's Hub Model: Calling for Perceptions and Feedback from those Clients at the Focus of Collaborative Risk-Driven Intervention
}

\author{
Chad Nilson*
}

In 2012, the province of Saskatchewan saw the human service professions of policing, mental health, addictions, education, and corrections, among others, begin a fundamental shift in the way they do business. As some strategists claim (SPSS Enterprise Group, 2011), there was a demonstrable need for human service professionals not only to collaborate in their efforts, but together, also focus on immediate mitigation of risks that lead to harm, thereby improving community safety and well-being in the long run. Responding to this need, human service professionals in Prince Albert, Saskatchewan, developed and mobilized what has since become known nationally as The Hub Model (McFee \& Taylor, 2014).

\section{The Hub Model}

The Hub Model represents a gathering of human service professionals who typically meet once or twice a week to detect acute elevations in complex client risk, share limited information necessary to identify client needs, and plan rapid interventions designed to mitigate those risks before harm occurs (Nilson, 2014). The Hub Model was designed as an upstream, interventionist approach to community safety and well-being that would allow human service providers from multiple sectors to collaborate around the improvement of client outcomes.

The original architects of the Hub Model (Mcfee \& Taylor, 2014) explain that observations of community collaboration efforts in Glasgow, Scotland were confirmation that human service professionals from multiple disciplines could work together. Furthermore, past evidence from Boston's Operation Ceasefire (Braga \& Wesiburd, 2012) and other applications of the Pulling Levers Deterrence Strategy (Engel, 2013; McGarrell \& Chermak, 2003; Papachristos, Meares \& Fagon, 2007)—although quite different from Canada's Hub Model-demonstrated that multiple human service professionals can reduce harm by mobilizing supports around individuals showing elevations in risk. These assurances, combined with the shared desire to "do better", prompted community leaders in Prince Albert to launch the Hub Model in 2011 (McFee \& Taylor, 2014).

In practice, the Hub Model facilitates the sharing of client information in a way that protects privacy. In fact, working within the confines of several privacy regulation frameworks, the Hub Model's Four Filter Process has allowed collaborators to mitigate risk while upholding several key principles of information sharing within the context of community safety and well-being (Russell \& Taylor, 2014). This has allowed human service providers to step beyond their traditional government silos and collaboratively find innovative ways to help clients like never before (Brown \& Newberry, 2015).

There are essentially three parts to the Hub Model. The first is an internal process of risk detection that human service agencies adopt in their day-to-day service delivery. Where single agencies cannot address composite risk alone, they approach the second part of the Hub Model—the discussion process. This highly disciplined process allows human service professionals to systematically share client information while complying with their respective privacy regulation frameworks. The third part of the Hub Model involves a multi-sector intervention that consists of a largely non-scripted, custommade opportunity to offer clients support in a non-coercive fashion. Following this intervention, or "door knock", members of the intervention team report back to the larger table, and the group collectively determines if sufficient steps have been taken to close the discussion (Nilson, 2016a).

\section{Existing Research on the Hub Model}

Since the launch of the Hub Model in Prince Albert in 2011, dozens of communities across Canada have replicated these efforts through forms of collaborative risk-driven intervention (Kalinowski, 2016; Russell \& Taylor, 2015). Following many of these replications has been the analysis of Hub data (Lamontagne, 2015; North Bay Parry Sound District Health Unit, 2015; Nilson, 2016b; Winterberger, 2015), along with a variety of evaluations (Babayan, Landry-Thompson \& Stevens, 2015; Brown \& Newberry, 2015; Lansdowne Consulting Group, 2016; Litchmore, 2014; Ng \& Nerad, 2015; Nilson, 2014; Nilson 2016c; Nilson 2016d)_all of which have helped inform our understanding of the Hub Model, its process, outputs, and preliminary outcomes.

Early narratives on the model (McFee \& Taylor, 2014; Nilson, 2014) helped to conceptualize and document the 
discipline and process of the Hub Model. Other contributions to the literature focused on early replications of the Hub Model in large urban areas (Ng \& Nerad, 2015), as well as small rural communities (Nilson, 2016c). Previous examinations of the Hub Model have also reported on early outcomes, including: increased access to services (Nilson, 2014); quicker access to services (Litchmore, 2014); better understandings of client needs (Babayan et al., 2015); improved communication among agencies (Ng \& Nerad, 2015); reduced barriers to support from human service agencies (Brown \& Newberry, 2015); identified gaps in the human service delivery system (Brown \& Newberry, 2015; Nilson 2015a); increased efficiencies in human service delivery (Lansdowne Consulting, 2016); and improved client-service provider relations (Nilson, 2016d). Beyond evaluation, ongoing analyses of Hub data have been highly informative on the risk factors affecting Hub subjects (Lamontagne, 2015; North Bay Parry Sound District Health Unit, 2015; Nilson, 2016b; Winterberger, 2015).

In much of the research and evaluation on this model, the perspectives and feedback gathered to develop data have largely come from human service providers and/or their management teams. In fact, only two evaluation efforts to date (Newberry \& Brown, forthcoming; Nilson, 2016d) have successfully gathered data from actual clients involved in Hub discussions. Some of the reasons given for the lack of data from client subjects of Hub discussions include a lack of follow-up with clients in the Hub discussion process (Brown \& Newberry, 2015), as well as limitations in data collection capacity at the local level (Babayan et al., 2015).

Despite these challenges in collecting data from clients, research and evaluation in other fields (Beinecke \& Delman, 2008; Bloom, 2010; Clark, Scott \& Krupa, 1993) has demonstrated that gathering data from clients of social interventions is a critical part of understanding the impact, strength, and weakness of that particular intervention. In fact, larger evaluation frameworks focused on community safety and well-being (Nilson, 2015b) have also called for methodologies to involve intervention clients as key data sources.

\section{Gathering Data from the Subjects of Collaborative Risk-Driven Intervention}

To fill this void, this commentary calls for researchers, evaluators, analysts, and human service professionals to work together in identifying opportunities for data to be gathered from the actual subjects of collaborative risk-driven intervention. Cooperation with human service professionals will be absolutely critical in gaining access to the preferred study cohort. Of course, the involvement of human service professionals in accessing clients does come with the risk of sample bias and even potential response bias among respondents. However, with proper sampling, survey and/or interview methodology, some of these limitations can be overcome.

In using discussion subjects as data sources, the research and evaluation community may wish to explore a variety of topics including client perception, satisfaction, change, impact, overall concerns, and suggestions for improvement. Being able to understand the impact of collaborative risk-driven intervention on clients and their families, from the perspective of Hub subjects themselves, will certainly validate (and/or challenge) the existing research to date. Additionally, gathering perspectives and feedback from clients at the focus of Hub discussions will enlighten our understanding of how well interventions are received, what makes them effective, the time duration and sustainability of their effects, and what can be done to improve collaborative risk-based client service delivery in general.

\section{CONFLICT OF INTEREST DISCLOSURES}

The author holds a business relationship with the Editor-in-Chief of this Journal.

\section{AUTHOR AFFILIATIONS}

*Global Network for Community Safety, Toronto, ON.

\section{REFERENCES}

Babayan, A., Landry-Thompson, T., \& Stevens, A. (2015). Evaluation of the Brant Community Response Team Initiative: six-month report. Brantford, ON: Brant County Health Unit.

Beinecke, R., \& Delman, J. (2008). Commentary: Client involvement in public administration research and evaluation. The Public Sector Innovation Journal, 13(1). Retrieved from http://www.innovation.cc/scholarly-style/ beinicke_7_commenta-_client_public_admin.pdf

Bloom, M. (2010). Client-centred evaluation: Ethics for $21^{\text {st }}$ century practitioners. Journal of Social Work Values and Ethics, 7(1).

Braga, A., \& Weisburd, D. (2012). The effects of "pulling levers" focused on deterrence strategies on crime. Cambridge, MA: Campbell Systematic Reviews.

Brown, J., \& Newberry, J. (2015). An evaluation of the Connectivity Situation Tables in Waterloo Region. Evaluation report submitted to Waterloo Region Connectivity Partnership. Guelph, ON: Taylor Newberry Consulting.

Clark, C., Scott, E., \& Krupa, T. (1993). Involving clients in programme evaluation and research: A new methodology for occupational therapy. Canadian Journal of Occupational Therapy, 60(4):192-199.

Engel, R. (2013). Establishing partnerships to reduce violence: The Cincinnati experience. CEBCP-SIRP Joint Symposium held at George Mason University Arlington Campus. Cincinnati, OH: Institute of Crime Science, University of Cincinnati. Retrieved from http://cebcp.org/wp-content/ Symposium2013/Engel

Kalinowski, B. (2016). Getting the right care, at the right time: If we want to change the outcomes, we may have to change ourselves. Canadian Police Chief Magazine, winter:25-26

Lamontagne, E. (2015). Rapid mobilization table data analysis update February, 2015. Sudbury, ON: Community Mobilization Sudbury.

Lansdowne Consulting. (2016). Multiagency early risk intervention tables (MERIT): Pilot project review. Ottawa, ON: The Lansdowne Consulting Group.

Litchmore, R. (2014). Preliminary report on the progress of the Guelph Situation Table. Internal Report Provided to Guelph Situation Table. Guelph, ON: University of Guelph

McFee, D., \& Taylor, N. (2014). The Prince Albert Hub and the emergence of collaborative risk-driven community safety. Change and Innovation in Canadian Policing: Canadian Police College Discussion Paper Series. Ottawa, ON: Canadian Police College.

McGarrell, E., \& Chermak, S. (2003). Problem solving to reduce gang and drug-related violence in Indianapolis. In Decker, S. (ed.). Police gangs and youth violence, p.77-101. Belmont, CA: Wadsworth Publishing Company.

Newberry, J., \& Brown, J. (forthcoming). Phase II Evaluation of the Connectivity Situation Tables in Waterloo Region. Evaluation report being prepared for Waterloo Region Connectivity Partnership. Guelph, ON: Taylor Newberry Consulting.

Ng, S., \& Nerad, S. (2015). Evaluation of the FOCUS Rexdale Pilot Project. Delivered to the City of Toronto and Toronto Police Service. Toronto, ON: Vision and Results Inc. and SN Management.

Nilson, C. (2014). Risk-Driven collaborative intervention: A preliminary impact assessment of Community Mobilization Prince Albert's Hub Model. 
Saskatoon, SK: Centre for Forensic Behavioural Science and Justice Studies, University of Saskatchewan.

Nilson, C. (2015a). The original game changers: An evaluative report on Prince Albert's Centre of Responsibility and its role in the advancemen of community mobilization efforts to improve community safety and wellness. Saskatoon, SK: Centre for Forensic Behavioural Science and Justice Studies, University of Saskatchewan.

Nilson, C. (2015b). Measuring change: A framework to support evaluation of collaborative risk-driven community safety and well-being in Ontario. Delivered to the Ontario Working Group on Collaborative Risk-Driven Community Safety. Prince Albert, SK: Living Skies Centre for Social Inquiry.

Nilson, C. (2016a). Technology-enabled Hubs in remote communities: A review of research and practice. Saskatoon, SK: Centre for Forensic Behavioural Science and Justice Studies, University of Saskatchewan.

Nilson, C. (2016b). Year One Analysis: A descriptive review of data captured through Collaborate Barrie's collaborative risk-driven intervention initiative. Toronto, ON: Global Network for Community Safety.

Nilson, C. (2016c). Collaborative risk-driven intervention: A study of Samson Cree Nation's application of the Hub model. Ottawa, ON: Public Safety Canada.

Nilson, C. (2016d). Collaborative risk-driven intervention evaluation brief: A preliminary analysis of discussion subject and table discussant satisfaction understanding and perceived impact of Collaborate Barrie's efforts to mitigate acutely-elevated risk. Toronto, ON: Global Network for Community Safety.
North Bay Parry Sound District Health Unit. (2015). North Bay Gateway Hub: Data Analysis 1-year Report. North Bay, ON: North Bay Parry Sound District Health Unit.

Papachristos, A., Meares, T., \& Fagan, J. (2007). Attention felons: Evaluating Project Safe Neighbourhoods in Chicago. Journal of Empirical Legal Studies, 4(2):223-272.

Russell, H., \& Taylor, N. (2014). New directions in community safetyconsolidating lessons learned about risk and collaboration. Ontario Working Group on Collaborative Risk-Driven Community Safety. Ottawa, ON: Ontario Association of Chiefs of Police.

Russell, H., \& Taylor, N. (2015). Gaining momentum: Multi-sector community safety and well-being in Ontario. Report Prepared for the Ontario Working Group on Collaborative Risk-Driven Community Safety and Well-being. Ottawa, ON: Ontario Association of Chiefs of Police.

SPPS Enterprise Group. (2011). Global literature and experience in wholeof-government approaches to crime and violence reduction: An interpretive report on the development and meta-analysis of an annotated bibliographic database for provincial policy makers. Development for the Saskatchewan Police and Partners Strategy. Regina, SK: Government of Saskatchewan.

Winterberger, M. (2015). Report on the Hub discussion 2013/2014: A documentation of the Prince Albert Hub discussion study period: September 1, 2013 to August 31, 2014. Prince Albert, SK: Community Mobilization Prince Albert. 